OPEN ACCESS

Edited by:

Ruiqing Ni,

ETH Zürich, Switzerland

Reviewed by:

Hidehiko Okazawa

University of Fukui, Japan

Sachchida Nand Rai,

University of Allahabad, India

*Correspondence:

Martin Klietz

klietz.martin@mh-hannover.de

tThese authors have contributed

equally to this work

Received: 23 August 2021 Accepted: 11 October 2021

Published: 01 November 2021

Citation:

Klietz M, Elaman MH,

Mahmoudi N, Nösel P, Ahlswede M,

Wegner F, Höglinger GU, Lanfermann H and Ding X-Q (2021)

Cerebral Microstructural Alterations in Patients With Early Parkinson's Disease Detected With Quantitative

Magnetic Resonance Measurements.

Front. Aging Neurosci. 13:763331

doi: 10.3389/fnagi.2021.763331

\section{Cerebral Microstructural Alterations in Patients With Early Parkinson's Disease Detected With Quantitative Magnetic Resonance Measurements}

\author{
Martin Klietz ${ }^{1 * \dagger}$, M. Handan Elaman ${ }^{2 \dagger}$, Nima Mahmoudi ${ }^{2}$, Patrick Nösel${ }^{2}$, \\ Mareike Ahlswede ${ }^{2}$, Florian Wegner ${ }^{1}$, Günter U. Höglinger ${ }^{1}$, Heinrich Lanfermann ${ }^{2}$ and \\ Xiao-Qi Ding²
}

${ }^{1}$ Department of Neurology, Hannover Medical School, Hanover, Germany, ${ }^{2}$ Institute of Diagnostic and Interventional Neuroradiology, Hannover Medical School, Hanover, Germany

Objective: Parkinson's disease (PD) is the second most common neurodegenerative disease in the elderly. In early stages of PD, patients typically display normal brain magnet resonance imaging (MRI) in routine screening. Advanced imaging approaches are necessary to discriminate early PD patients from healthy controls. In this study, microstructural changes in relevant brain regions of early PD patients were investigated by using quantitative MRI methods.

Methods: Cerebral MRI at 3T was performed on 20 PD patients in early stages and 20 age and sex matched healthy controls. Brain relative proton density, T1, T2, and T2' relaxation times were measured in 14 regions of interest (ROIs) in each hemisphere and compared between patients and controls to estimate PD related alterations.

Results: In comparison to matched healthy controls, the PD patients revealed decreased relative proton density in contralateral prefrontal subcortical area, upper and lower pons, in ipsilateral globus pallidus, and bilaterally in splenium corporis callosi, caudate nucleus, putamen, thalamus, and mesencephalon. The $\mathrm{T} 1$ relaxation time was increased in contralateral prefrontal subcortical area and centrum semiovale, putamen, nucleus caudatus and mesencephalon, whereas T2 relaxation time was elevated in upper pons bilaterally and in centrum semiovale ipsilaterally. T2' relaxation time did not show significant changes.

Conclusion: Early Parkinson's disease is associated with a distinct profile of brain microstructural changes which may relate to clinical symptoms. The quantitative MR method used in this study may be useful in early diagnosis of Parkinson's disease. Limitations of this study include a small sample size and manual selection of the ROls. Atlas-based or statistical mapping methods would be an alternative for an objective evaluation. More studies are necessary to validate the measurement methods for clinical use in diagnostics of early Parkinson's disease.

Keywords: Parkinson's disease, relative proton density, T1 relaxation time, T2 relaxation time, T2' relaxation time, quantitative MRI analysis, biomarker, early diagnosis 


\section{INTRODUCTION}

The prevalence of Parkinson's disease (PD) in Germany is about $0.5 \%$ of the population, according to recently published data, which seems to be representative of industrial countries worldwide (Heinzel et al., 2018). Patients with PD experience a pronounced decrease in quality of life in the course of the disease (Klietz et al., 2018, 2020).

The main pathological processes in PD are known to include the deposition of Lewy bodies across the brain in a specific stage-related manner, and the loss of dopaminergic neurons innervating the basal forebrain via long unmyelinated axons (Halliday and McCann, 2010; Kalia and Kalia, 2015; Rai and Singh, 2020; Rai et al., 2020, 2021). This results in dopamine depletion in the basal forebrain and further maladaptive changes in neurotransmission, for example in striatal interneurons (Keber et al., 2015; Klietz et al., 2016).

Braak et al. (2004) described brain Lewy body pathology as an ascending process beginning in the dorsal nucleus of the vagal nerve in stage I, reaching substantia nigra dopaminergic neurons in stage III and, finally, covering the majority of the cerebral cortex in stages V and VI (Braak et al., 2004; Rai et al., 2016, 2017; Braak and Tredici, 2017). Despite a few weaknesses, the Braak model is still the most widely accepted theory of progression of Lewy pathology in PD (Jellinger, 2019). Alpha-synuclein is a relevant component of Lewy bodies and there is growing evidence showing a spread of misfolded oligomeric alpha-synuclein fibrils over the brain contributing to PD progression via neuronal toxicity (Olanow and Prusiner, 2009). Alpha-synuclein unfolds its toxic properties in various cell components. First, alphasynuclein impairs the mitochondrial function (Sheng and Cai, 2012). Additionally, it disturbs intracellular protein homeostasis, leading to chronic endoplasmic reticulum stress (Burré et al., 2018). Further, it can form pore-like structures that perforate membranes including the plasma membrane (Stöckl et al., 2013; Angelova and Abramov, 2017). Several studies also describe mild inflammatory reactions as a component of PD pathology (Zhang et al., 2005; Alvarez-Erviti et al., 2011; Depboylu et al., 2011a,b).

In the differential diagnosis of PD, magnetic resonance imaging (MRI) is an important tool (Meijer and Goraj, 2014). However, PD patients typically present a normal routine MRI scan and only patients with atypical Parkinsonism may show specific imaging features (Yekhlef et al., 2003). Since standard MRI measures do not discriminate healthy controls from PD patients, advanced imaging methods are needed for detection of PD related brain changes with higher sensitivity (Huppertz et al., 2016; Fu et al., 2020). Therefore, patients at different PD stages were studied with combined multiple parametric MRI and MR spectroscopic imaging methods (Klietz et al., 2019a; Fu et al., 2020). In this study, quantitative MRI measurements were used to study PD patients at an early stage.

Quantitative MRI (qMRI) measurements could be used to determine brain tissue parameters, such as relative proton density that is related to tissue free water content, relaxation time T1 characterizing the longitudinal relaxation process, $\mathrm{T} 2, \mathrm{~T} 2^{\prime}$, and $\mathrm{T}^{*}$ that describe the irreversible (T2), reversible $\left(\mathrm{T}^{\prime}\right)$ and apparent transverse relaxation processes (T2*) (Eylers et al., 2016; Gracien et al., 2019). Pathological conditions may cause altered values of these parameters: Proton density changes, for example due to edema (Jurcoane et al., 2013; Carey et al., 2018; Tofts, 2018; Filo et al., 2019). T1, T2, T2*, and T2' relaxation times may provide information about various tissue properties like water and iron content, degree of myelination, axonal damage, and gliosis (Fatouros et al., 1991; Gelman et al., 1999, 2001; Brex et al., 2000; Laule et al., 2004; Lutti et al., 2014; Waehnert et al., 2016), as well as the local concentration of deoxyhemoglobin or metabolic activity of the brain tissue (Wagner et al., 2012; Eylers et al., 2016). Therefore, qMRI measurement may be a potential tool for detection of early brain changes in PD patients. Recent studies in Alzheimer's disease showed similarly that detection of early cerebral microstructural changes using MRI relaxation methods can be useful in the early diagnosis of the disease, potentially providing a non-invasive biomarker for Alzheimer's disease which can also predict cognitive decline in the course of disease development (Reas et al., 2018; Wearn et al., 2020).

Until now, few structured 3T qMRI analyses of a carefully characterized PD cohort compared to healthy controls are available (Langkammer et al., 2016; Nürnberger et al., 2017; Chen et al., 2019). The aim of the present study is to estimate the feasibility of using qMRI measurements to detect brain changes in patients with early PD.

\section{PATIENTS AND METHODS}

\section{Patients and Clinical Examinations}

This study was conducted with ethical approval of the local Ethics Committee of Hannover Medical School (No. 61672016). All patients and participants gave their written informed consent. Patients were recruited from the neurological wards, the outpatient clinic and from local patient support groups. The diagnosis of PD was confirmed according to the Movement Disorder Society (MDS) diagnostic criteria for PD by a movement disorder specialist (Postuma et al., 2015). For none of the PD patients an alternative diagnosis was more likely than PD.

Only early-stage PD patients, who were scaled clinically with Hoehn and Yahr stages (H\&Y) of 1 or 2 in the best medical "on" state and aged 75 or below, were included in the study. Definition of early-stage PD by the H\&Y stages is in accordance with earlier studies of our group (Klietz et al., 2019a; Fu et al., 2020), additionally, none of our patients complained of a significant amount of motor complications qualifying for advanced PD (Titova et al., 2017). Patients with atypical Parkinsonism and other known brain pathologies, e.g., stroke, small vessel disease, or tumor, were not included in this study. Patients with clinical conditions interfering with MRI diagnostics, like severe head tremor, dystonia or dyskinesia, had to be excluded as well. PD patients with severe comorbidities were also excluded from our study (Klietz et al., 2019b; Greten et al., 2020).

Twenty PD patients (48-72 years old, mean age $60.2 \pm 7.2$ years, 12 females) were included. Disease specific information like disease duration, dominantly affected body side, predominant symptoms, general and PD medication 
and comorbidities were documented. 16 of $20 \mathrm{PD}$ patients underwent a dopamine transporter (DAT) scan in the diagnostic work up in routine care, in all cases the DAT scan revealed lateralized nigro-striatal dopaminergic neurodegeneration. PD specific symptoms were assessed by the Movement Disorder Society Unified Parkinson's Disease Rating Scale (MDS-UPDRS) (Goetz et al., 2008). Patients were rated in best medication "on" state. PD specific medication was noted and levodopa equivalence dosage calculated (LED) (Tomlinson et al., 2010). Cognitive deficits were quantified by the established test for dementia and mild cognitive impairment "DemTect" (Kalbe et al., 2004). 20 healthy participants matched in age and sex on a one-to-one basis were also studied as the control cohort. All patients and healthy controls were right-handed according to self-report.

Part of this early PD patient cohort was studied previously with other MRI methods (Klietz et al., 2019a; Fu et al., 2020). Patient characteristics showed some differences as one patient was replaced due to incomplete MRI scans.

\section{MR Examinations and Data Processing}

All subjects underwent MR examinations at 3T (Verio, Siemens, Erlangen, Germany), with the routine MRI protocol including the following sequences for subsequent qMRI measurements: a T2 weighted turbo spin echo (T2-TSE) sequence with three echoes (triple TE) $\left(\mathrm{TR} / \mathrm{TE}=6640 / 8.7 / 70 / 131 \mathrm{~ms} ; 150^{\circ}\right.$ flip angle; $256 \times 208$ matrix; $1 \mathrm{~mm} \times 1 \mathrm{~mm} \times 3 \mathrm{~mm}$ voxel size), a T2 weighted gradient echo (T2-GRE) sequence with triple TE $\left(\mathrm{TR} / \mathrm{TE}=1410 / 6.42 / 18.42 / 30.42 \mathrm{~ms} ; 20^{\circ}\right.$ flip angle; $256 \times 208$ matrix; $1 \mathrm{~mm} \times 1 \mathrm{~mm} \times 3 \mathrm{~mm}$ voxel size), a T1 weighted three-dimensional GRE (T1-GRE) sequence with two flip angles $\left(\mathrm{T} 1 \mathrm{wGRE}, \mathrm{TR} / \mathrm{TE}=15 / 1.64 \mathrm{~ms}\right.$, flip angles $5^{\circ}$ and $25^{\circ} ; 256 \times 208$ matrix; $1 \mathrm{~mm} \times 1 \mathrm{~mm} \times 3 \mathrm{~mm}$ voxel size), and a fluid attenuation inversion recovery (FLAIR) sequence. The scans were obtained with the same angulation enabling identifications of the same brain structures. An aqueous phantom was also scanned with the Triple TE sequence to derive proton density of the phantom $\left(\mathrm{PD}_{\mathrm{H} 2 \mathrm{O}}\right)$, which was used for normalization of the proton density measured from subjects.

The inspection of FLAIR, TSE and GRE images to identify possible morphological abnormalities was completed by two independent neuroradiologists. Participants with morphological MRI abnormalities were excluded from this study. Parameter maps of the relaxation times T1, T2, and T2* were obtained onthe-fly by the MR console with an extended image reconstruction, provided by the manufacturer, with monoexponentially fitting to the signal-intensity decay curves based on the data acquired with T1-GRE, T2-TSE and T2-GRE sequences, respectively. The maps of $\mathrm{T} 2$ ' were derived according to the equation $1 / \mathrm{T} 22^{\prime}=1 / \mathrm{T} 2+1 / \mathrm{T} 2 *$. The derived brain maps of proton density, $\mathrm{T} 1, \mathrm{~T} 2$, and $\mathrm{T} 2{ }^{\prime}$ were used for region of interest analysis.

\section{Region of Interest Analysis}

In each subject, the values of proton density, T1, T2, and T2' were determined by using mean values over a region of interest (ROI). In total, 28 ROIs (14 in each brain hemisphere) were selected in consideration of their neuroanatomical functions and the involvement in Parkinson's disease, and were located bilaterally in the prefrontal subcortical area, subcortical primary motor area, supplementary motor area, centrum semiovale, splenium corporis callosi, nucleus caudatus, putamen, globus pallidus, thalamus, mesencephalon (containing substantia nigra and ventral tegmental area), upper and lower pons, cerebellar

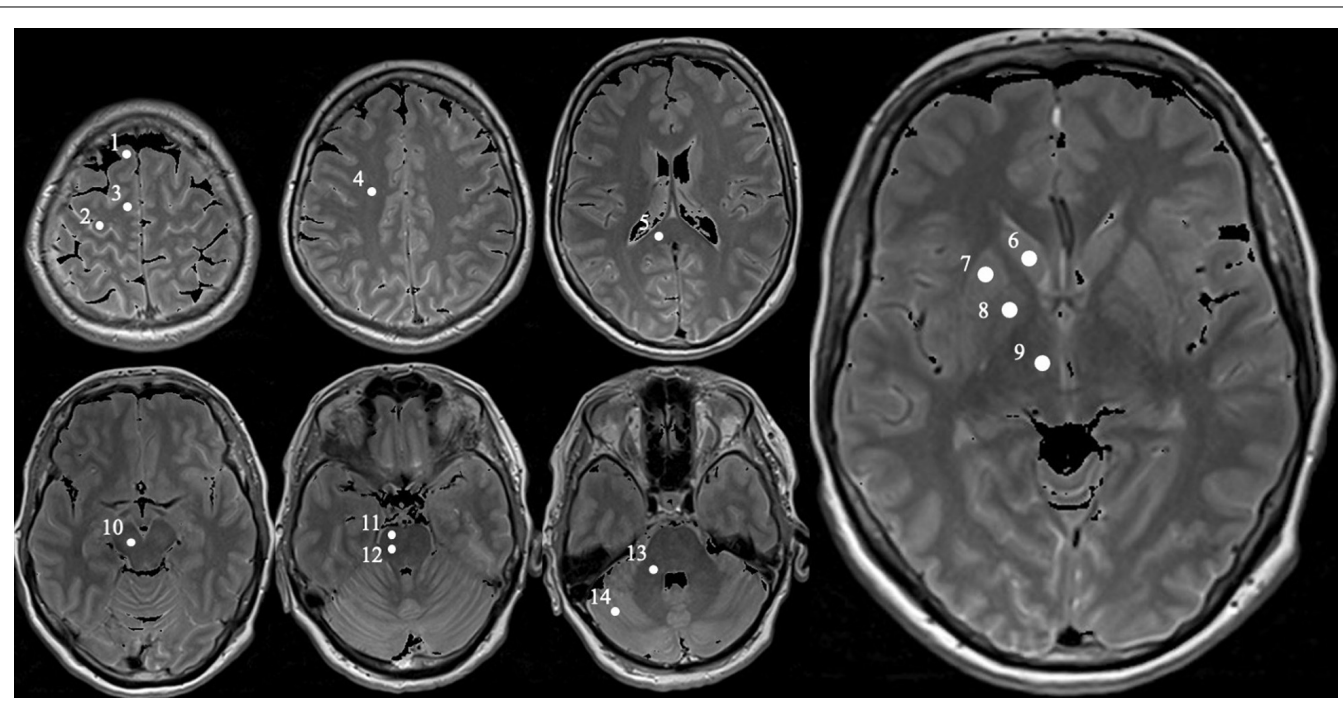

FIGURE 1 | Exemplary MRI with definition of the specific measured regions obtained from a PD patient (female, 62). Positions of each selected ROI in the right brain hemisphere marked as white circle on proton density weighted MR images obtained from a 62-year-old female Parkinson's disease patient. The circles are numbered 1 to 14, representing the following ROls: prefrontal subcortical area (1), subcortical primary motor area (2), supplementary motor area (3), centrum semiovale (4), splenium corporis callosi (5), nucleus caudatus (6), putamen (7), globus pallidus (8), thalamus (9), mesencephalon (containing substantia nigra and ventral tegmental area, 10), upper and lower pons (11 and 12, respectively), cerebellar white matter (13), and cerebellar posterior lobe (14). 
white matter, and cerebellar posterior lobe (Figure 1). The relevant substantia nigra area is very small so that a ROI covering only this part would lead to erroneous measurements due to unavoidable partial volume effects. Hence, a ROI with a larger area in the ventral mesencephalon covering the substantia nigra fully was selected and named "mesencephalon," as this region covers also the surrounding midbrain parts in addition to the substantia nigra.

All ROIs were carefully drawn manually as a circle of about $20 \mathrm{~mm}^{2}$ according to anatomical landmarks. Subsequently, the values of relative proton density $\left(=\right.$ measured value $/ \mathrm{PD}_{\mathrm{H} 2 \mathrm{O}}$ presented in $\%$ ), T1, T2, and $\mathrm{T} 2$ ' were obtained from each of the ROIs (Figure 2). All derived data were controlled by the following quality criteria: Values of the ROIs measured from brain tissue parameter maps with a coefficient of variation (= standard deviation/mean value, COV) higher than $25 \%$ were excluded from further statistical analysis.

\section{Statistical Analysis}

The measured data were statistically compared between patients and healthy controls. The data measured from left and right brain hemispheres of the PD patients were rearranged into data of contralateral or ipsilateral hemispheres in regard to the symptom onset body side for the comparison. In order to minimize possible bias related to natural hemisphere laterality in the human brain, we used hemisphere-matched data of healthy controls as reference data. For example, for a PD patient with right dominant clinical symptoms, the right cerebral hemisphere is ipsilateral to the clinically pronounced side. Accordingly, in the healthy volunteer the right hemisphere was viewed ipsilateral and the left as contralateral, for conformity. After the normality of the data distribution was checked with ShapiroWilk test and quantile-quantile plots, a paired $t$-test was used to compare the measured values between patients and the matched healthy controls. The comparison was made both for the data of the contralateral and the data of the ipsilateral hemisphere. False-discovery rate (FDR) with a desired false-discovery rate of 0.05 was used for multiple comparison correction (Benjamini and Hochberg, 1995), with a corresponding FDR corrected significance threshold of $\mathrm{pi}=0.05 / \mathrm{i}$, $\mathrm{i}$ varied from $\mathrm{n}, \mathrm{n}-1, \ldots$ to 1 , where, $n=14$, the number of multiple testing that was equal to the number of the ROIs in each hemisphere. Results with a p less than 0.05 were controlled with FDR, where those with a p less than the corresponding pi were considered significant cases, and those with a $\mathrm{p}$ larger than the corresponding pi were considered not significant. Spearman's correlation test with a significance level of 0.05 was used to estimate possible correlations between clinical MDSUPDRS scores and significantly altered brain parameter values in $\mathrm{PD}$ patients.

Statistical analyses were performed with SPSS version 23 (SPSS IBM, New York, United States).

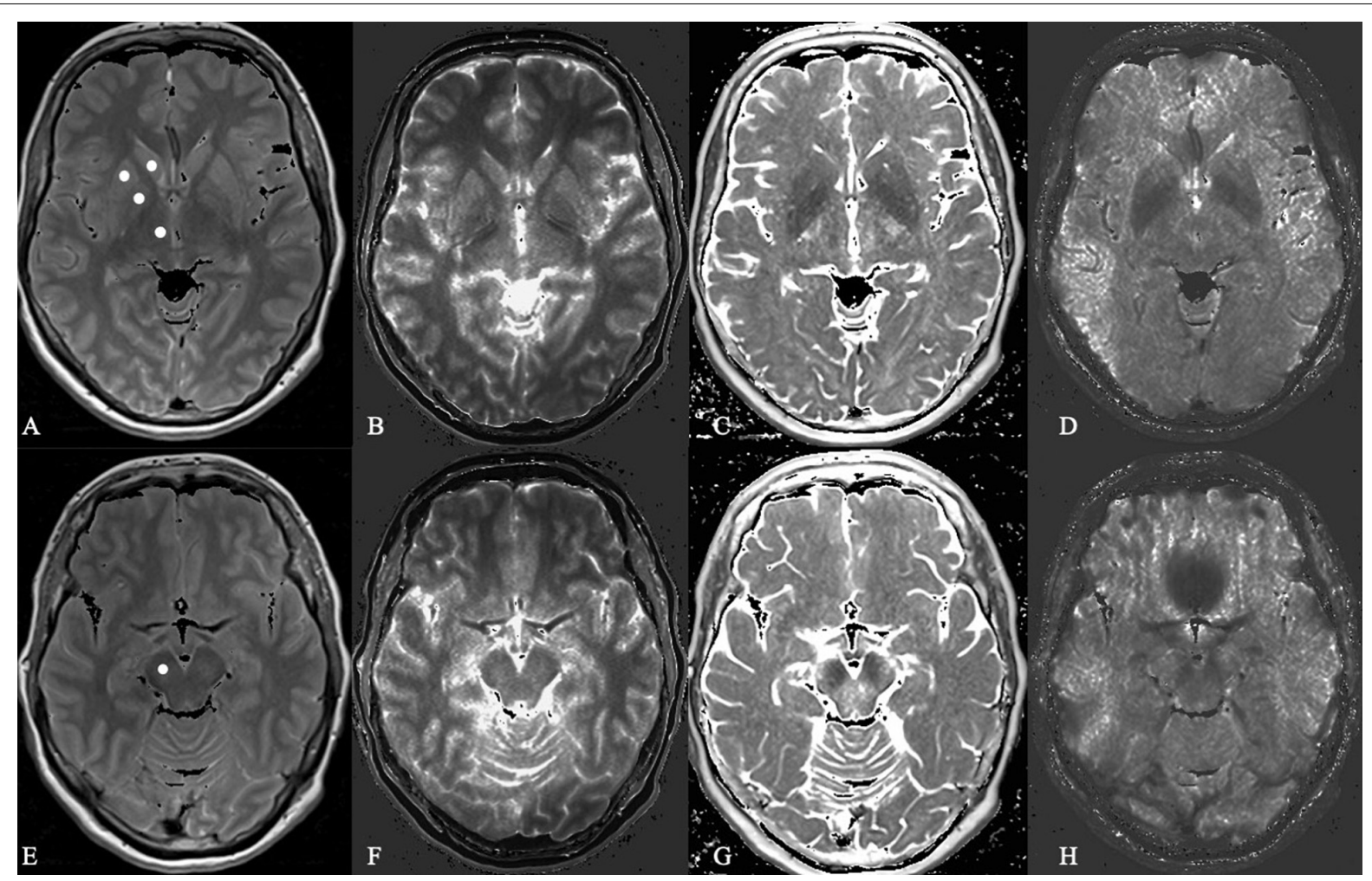

FIGURE 2 | Microstructural analysis of proton density, T1 relaxation time, T2 and T2 prime in a Parkinson's disease patient. In this Figure shows the basal ganglia (A-D) and mesencephalon (E-H) in proton density-weighted (A,E), T1-weighted (B,F), T2-weighted (C,G), and T2 prime-weighted (D,H) MR sequences obtained from a 62-year-old female PD patient. 


\section{RESULTS}

\section{Parkinson's Disease Patient Characteristics}

20 early stage clinically diagnosed PD subjects were included in this study. None of the patients were suspected to suffer from atypical Parkinsonism or were cognitively impaired. All patients reported an obviously positive response to dopaminergic treatment and were examined in the best medication "on" state. All PD patient characteristics are displayed in Table 1. All PD subjects revealed good cognitive function measured by the DemTect with a mean score of 16.0 (SD 1.9, min 13 and max 18). The patients displayed a mean value of 7.4 (SD 4.4, $\min 2, \max 17)$ in MDS-UPDRS part II as motor aspects of daily living. Motor deficits in the best medication "on" state of our PD subjects in the MDS-UPDRS part III scored a mean of 16.5 points (SD 7.9, $\min 5$ and $\max 31$ ).

\section{Quantitative MR Measurements}

Tables 2-5 show the results of paired $t$-tests between PD patients and matched controls for relative proton densities, T1, T2, and $\mathrm{T} 2$ ', measured from contralateral and ipsilateral hemispheres of the patients in relation to the clinically affected/more affected body hemisphere as well as from the corresponding matched hemisphere of the healthy controls.

In comparison to matched healthy controls, our patients revealed significant decreases $(p<0.05$ and pi) of brain relative proton density in 8 of 14 contralateral ROIs (contralateral prefrontal subcortical area, splenium corporis callosum, caudate nucleus, putamen, thalamus, mesencephalon, upper and lower pons), and 6 of 14 ipsilateral ROIs (ipsilateral splenium corporis callosum, caudate nucleus, putamen, globus pallidus, thalamus, and mesencephalon), while showing a trend to decrease (pi $<p<0.05$, not significant after correction for multiple testing) in five ROIs, including contralateral globus pallidus, and ipsilateral subcortical primary motor area, centrum semiovale, upper and lower pons (Table 2).

TABLE 1 | Patient characteristics.

\begin{tabular}{lcccc}
\hline & Mean & SD & Min & Max \\
\hline 12 females, 8 males & & & & \\
Clinically dominant side: 12 right, 8 left & & & & \\
Type: 8 ET, 8 TD, 4 AR & & & & \\
H\&Y stage & 1.8 & 0.5 & 1 & 2 \\
Disease duration (in years) & 6.0 & 3.7 & 1 & 13 \\
MDS-UPDRS part I & 7.7 & 4.5 & 2 & 20 \\
MDS-UPDRS part II & 7.4 & 4.4 & 2 & 17 \\
MDS-UPDRS part III & 16.5 & 7.9 & 5 & 31 \\
MDS-UPDRS part IV & 0.4 & 1.1 & 0 & 4 \\
DemTect & 16.0 & 1.9 & 13 & 18 \\
LED & $770 \mathrm{mg}$ & $521 \mathrm{mg}$ & $0 \mathrm{mg}$ & $1,600 \mathrm{mg}$
\end{tabular}

H\&Y Hoehn and Yahr stage; MDS-UPDRS Movement Disorders Society Unified Parkinson's Disease Rating Scale; DemTect test for cognitive assessment; ET equivalence type; TD tremor dominant; AR akinetic-rigid; LED Levodopaequivalence dosage.
Compared to healthy controls, our PD patients also revealed a significant increase of T1 relaxation time $(p<0.05$ and $\mathrm{pi})$ in three contralateral ROIs and in one ipsilateral ROI (contralateral prefrontal subcortical area, centrum semiovale, splenium corpus callosum, and ipsilateral centrum semiovale). Additionally, the data showed a trend to increase ( $\mathrm{pi}<p<0.05$, not significant after correction for multiple testing) in five contralateral and four ipsilateral ROIs (contralateral subcortical primary motor area, supplementary motor area, caudate nucleus, putamen, and mesencephalon, and ipsilateral prefrontal subcortical area, splenium corpus callosum, putamen, and upper pons, Table 3).

Furthermore, in comparison to healthy controls, the PD patients revealed a significant increase of $\mathrm{T} 2$ relaxation time $(p<0.05$ and pi) in one contralateral and 2 ipsilateral ROIs (contralateral upper pons, and ipsilateral splenium corpus callosum and upper pons), and showed a trend to increase (pi $<p<0.05$, not significant after correction for multiple testing) in ipsilateral cerebellar white matter (Table 4).

No significant difference between patients and healthy controls was found in $\mathrm{T} 2^{\prime}$ relaxation time, while a trend to altered $\mathrm{T}^{\prime}(p<0.05$ and $\mathrm{pi}$ ) was found in four contralateral ROIs of the PD patients, including a trend to increase in contralateral splenium corpus callosum and globus pallidus, and a trend to decrease in contralateral supplementary motor area and mesencephalon (Table 5).

Spearman's correlation test revealed significant correlations between altered qMRI parameters and clinically observed MDSUPDRS scores in our patients: There were significant correlations between MDS-UPDRS part I and relative proton density (Table 6) in contralateral prefrontal subcortical area $(R=-0.458$, $p=0.042)$, in bilateral splenium corporis callosi $(R=0.468$ and $0.472, p=0.038$ and 0.042 , respectively), and T1 in contralateral splenium corporis callosi $(R=0.468, p=0.038)$, between MDSUPDRS part II and T1 in contralateral prefrontal subcortical area $(R=0.509, p=0.026)$, and relative proton density in contralateral nucleus caudatus $(R=-0.492, p=0.028)$, between MDS-UPDRS part IV as well as total MDS-UPSRS and $\mathrm{T} 1$ in contralateral prefrontal subcortical area $(R=0.475$ and $0.555, p=0.040$ and 0.014 , respectively) (T1 correlations not shown).

\section{DISCUSSION}

In the present study, relative proton density, $\mathrm{T} 1, \mathrm{~T} 2$, and $\mathrm{T} 2^{\prime}$ relaxation time were determined in early $\mathrm{PD}$ patients and in matched healthy controls from 28 brain regions of interest, which were selected based on their contribution to the nigrostriatal system, dopaminergic innervation or their brainstem localization. The derived values of these tissue parameters were compared between patients and controls with respect to the common asymmetric onset of PD. This allowed for the reorganization of ROIs in ipsilateral and contralateral brain hemispheres with regard to the clinical manifestation, as reported previously (Klietz et al., 2019a; Fu et al., 2020), depending on the body side with most pronounced symptoms and lateralized brain degeneration (Riederer and Sian-Hülsmann, 2012). 
TABLE 2 | Paired $t$-tests between patients and controls for relative proton densities measured in brain hemispheres contralateral or ipsilateral to the more affected body side as indicated.

\begin{tabular}{|c|c|c|c|c|c|c|c|c|c|c|c|}
\hline \multirow[t]{3}{*}{ Region of Interest } & \multirow{3}{*}{$N^{1}$} & \multicolumn{5}{|c|}{ Ipsilateral } & \multicolumn{5}{|c|}{ Contralateral } \\
\hline & & \multicolumn{2}{|c|}{ Patient } & \multicolumn{2}{|c|}{ Control } & \multirow[t]{2}{*}{$p$} & \multicolumn{2}{|c|}{ Patient } & \multicolumn{2}{|c|}{ Control } & \multirow[t]{2}{*}{$p$} \\
\hline & & Mean & SD & Mean & SD & & Mean & SD & Mean & SD & \\
\hline Prefrontal Subcortical Area & 19 & 49.78 & 3.72 & 47.14 & 4.99 & 0.07 & 50.47 & 3.14 & 46.77 & 3.74 & $0.0024^{\star *}$ \\
\hline Subcortical Primary Motor Area & 20 & 44.02 & 2.85 & 46.88 & 4.35 & $0.011^{\star}$ & 44.63 & 3.45 & 44.98 & 3.53 & 0.78 \\
\hline Supplementary Motor Area & 20 & 50.23 & 4.09 & 50.10 & 6.22 & 0.92 & 53.13 & 5.05 & 50.76 & 5.58 & 0.11 \\
\hline Centrum Semiovale & 20 & 42.78 & 2.39 & 44.68 & 2.91 & $0.011^{*}$ & 42.55 & 3.20 & 44.37 & 2.76 & 0.06 \\
\hline Splenium Corporis Callosi & 20 & 35.28 & 3.42 & 38.66 & 3.24 & $0.0002^{\star *}$ & 35.16 & 2.83 & 39.07 & 3.49 & $0.00003^{\star \star}$ \\
\hline Nucleus Caudatus & 20 & 51.46 & 3.48 & 54.70 & 3.28 & $0.0018^{\star \star}$ & 50.88 & 3.28 & 55.02 & 3.85 & $0.0013^{\star \star}$ \\
\hline Putamen & 20 & 50.40 & 4.30 & 54.07 & 3.63 & $0.002^{\star \star}$ & 51.06 & 2.55 & 54.44 & 3.61 & $0.0016^{\star \star}$ \\
\hline Globus Pallidus & 20 & 41.63 & 3.70 & 45.22 & 3.27 & $0.0009^{\star \star}$ & 41.26 & 3.34 & 44.32 & 3.34 & $0.0154^{\star}$ \\
\hline Thalamus & 20 & 43.46 & 3.21 & 48.79 & 4.27 & $0.00002^{\star \star}$ & 43.32 & 2.92 & 49.14 & 3.53 & $0.00002^{\star \star}$ \\
\hline Mesencephalon & 20 & 36.35 & 3.09 & 40.10 & 4.39 & $0.0023^{\star *}$ & 36.22 & 2.86 & 39.96 & 3.80 & $0.0041^{\star *}$ \\
\hline Upper Pons & 20 & 30.81 & 3.24 & 33.01 & 3.07 & $0.0182^{*}$ & 30.99 & 2.16 & 33.12 & 2.66 & $0.0062^{\star \star}$ \\
\hline Lower Pons & 20 & 33.03 & 4.30 & 35.46 & 3.57 & $0.0174^{\star}$ & 32.84 & 2.71 & 35.69 & 3.17 & $0.0052^{\star *}$ \\
\hline Cerebellar White Matter & 20 & 34.79 & 3.54 & 35.32 & 3.77 & 0.57 & 35.08 & 2.05 & 35.51 & 3.58 & 0.57 \\
\hline Cerebellar Posterior Lobe & 20 & 49.35 & 5.10 & 51.05 & 3.57 & 0.18 & 49.76 & 4.63 & 48.95 & 5.60 & 0.58 \\
\hline
\end{tabular}

${ }^{1}$ Number of patient-control pairs.

** Significant after correction for multiple comparisons by using false-discovery rate (FDR).

${ }^{*} p<0.05$ but not significant after FDR correction.

TABLE 3 | Paired $t$-tests between patients and controls for T1 relaxation times measured in brain hemisphere contralateral or ipsilateral to the more affected body side as indicated.

\begin{tabular}{|c|c|c|c|c|c|c|c|c|c|c|c|}
\hline \multirow[t]{3}{*}{ Region of Interest } & \multirow{3}{*}{$N^{1}$} & \multicolumn{5}{|c|}{ Ipsilateral } & \multicolumn{5}{|c|}{ Contralateral } \\
\hline & & \multicolumn{2}{|c|}{ Patient } & \multicolumn{2}{|c|}{ Control } & \multirow[t]{2}{*}{$p$} & \multicolumn{2}{|c|}{ Patient } & \multicolumn{2}{|c|}{ Control } & \multirow[t]{2}{*}{$p$} \\
\hline & & Mean & SD & Mean & SD & & Mean & SD & Mean & SD & \\
\hline Prefrontal Subcortical Area & 19 & $1,026.79$ & 191.32 & 849.45 & 159.89 & $0.0085^{\star}$ & $1,059.11$ & 184.49 & 869.33 & 123.54 & $0.0011^{\text {** }}$ \\
\hline Subcortical Primary Motor Area & 20 & 995.67 & 129.37 & 938.36 & 71.28 & 0.078 & 993.04 & 97.61 & 936.28 & 128.63 & $0.0488^{\star}$ \\
\hline Supplementary Motor Area & 19 & $1,187.13$ & 235.93 & $1,064.81$ & 249.25 & 0.19 & $1,232.19$ & 196.85 & $1,055.84$ & 289.86 & $0.0097^{\star}$ \\
\hline Centrum Semiovale & 20 & $1,126.00$ & 120.97 & 995.42 & 90.25 & $0.0011^{\star *}$ & $1,118.82$ & 119.01 & 996.74 & 120.52 & $0.0008^{\star \star}$ \\
\hline Splenium Corporis Callosi & 20 & $1,420.66$ & 123.40 & $1,293.15$ & 148.74 & $0.0052^{*}$ & $1,422.51$ & 142.67 & 1, 279.92 & 153.91 & $0.0023^{\star \star}$ \\
\hline Nucleus Caudatus & 20 & $2,002.53$ & 183.38 & 1, 938.72 & 188.31 & 0.27 & $2,111.10$ & 169.36 & $1,978.04$ & 148.02 & $0.0177^{\star}$ \\
\hline Putamen & 20 & $1,933.18$ & 173.99 & $1,795.14$ & 139.92 & $0.0102^{*}$ & $1,974.17$ & 164.92 & 1, 825.39 & 200.67 & $0.0203^{\star}$ \\
\hline Globus Pallidus & 20 & $1,612.88$ & 219.98 & $1,548.07$ & 174.52 & 0.33 & $1,634.94$ & 172.93 & $1,563.41$ & 211.27 & 0.24 \\
\hline Thalamus & 20 & $2,443.62$ & 331.26 & $2,375.49$ & 256.63 & 0.47 & $2,384.40$ & 307.89 & $2,309.73$ & 338.12 & 0.4 \\
\hline Mesencephalon & 19 & $1,863.19$ & 246.24 & $1,772.37$ & 162.36 & 0.17 & $1,861.59$ & 151.66 & $1,747.23$ & 180.17 & $0.0391^{*}$ \\
\hline Upper Pons & 20 & $1,863.93$ & 186.70 & $1,737.71$ & 156.43 & $0.0172^{*}$ & $1,845.78$ & 192.32 & $1,839.76$ & 181.69 & 0.9 \\
\hline Lower Pons & 20 & $1,981.60$ & 265.19 & $1,876.63$ & 191.22 & 0.16 & $1,893.47$ & 205.50 & $1,843.12$ & 235.43 & 0.4 \\
\hline Cerebellar White Matter & 20 & $1,693.94$ & 178.22 & $1,606.62$ & 182.62 & 0.15 & $1,535.96$ & 183.33 & $1,572.04$ & 194.26 & 0.49 \\
\hline Cerebellar Posterior Lobe & 20 & $1,678.96$ & 312.26 & $1,669.21$ & 186.02 & 0.9 & $1,471.78$ & 270.08 & $1,473.91$ & 262.18 & 0.98 \\
\hline
\end{tabular}

${ }^{1}$ Number of patient-control pairs.

**Significant after correction for multiple comparisons by using false-discovery rate (FDR).

${ }^{*} p<0.05$ but not significant after FDR correction.

The most obvious brain alteration observed was the decreased relative proton density in PD patients. A decrease of proton density occurred in 19 of 28 selected ROIs (bilateral splenium corporis callosi, caudate nucleus, putamen, globus pallidus, thalamus, mesencephalon, upper and lower pons, in contralateral prefrontal cortex, and in ipsilateral primary motor area and centrum semiovale) of the patients, indicating microstructural alterations of brain tissue in these regions. The previously mentioned PD-related pathological deposits may bind water, resulting in less free water in brain tissue, which may be a reason for decreased proton density in our patients. 
TABLE 4 | Paired $t$-tests between patients and controls for brain T2 relaxation times measured in brain hemisphere contralateral or ipsilateral to the more affected body side as indicated.

\begin{tabular}{|c|c|c|c|c|c|c|c|c|c|c|c|}
\hline \multirow[t]{3}{*}{ Region of Interest } & \multirow{3}{*}{$N^{1}$} & \multicolumn{5}{|c|}{ Ipsilateral } & \multicolumn{5}{|c|}{ Contralateral } \\
\hline & & \multicolumn{2}{|c|}{ Patient } & \multicolumn{2}{|c|}{ Control } & \multirow[t]{2}{*}{$p$} & \multicolumn{2}{|c|}{ Patient } & \multicolumn{2}{|c|}{ Control } & \multirow[t]{2}{*}{$\mathbf{p}$} \\
\hline & & Mean & SD & Mean & SD & & Mean & SD & Mean & SD & \\
\hline Prefrontal Subcortical Area & 14 & 137.32 & 16.57 & 146.20 & 18.29 & 0.22 & 132.25 & 22.50 & 142.55 & 16.30 & 0.14 \\
\hline Subcortical Primary Motor Area & 19 & 123.38 & 9.54 & 119.49 & 13.80 & 0.35 & 116.70 & 12.68 & 121.50 & 10.83 & 0.27 \\
\hline Supplementary Motor Area & 19 & 111.63 & 14.26 & 119.77 & 10.74 & 0.07 & 116.23 & 19.30 & 123.29 & 12.39 & 0.24 \\
\hline Centrum Semiovale & 20 & 124.06 & 9.70 & 127.91 & 7.52 & 0.16 & 123.49 & 11.45 & 127.12 & 9.21 & 0.3 \\
\hline Splenium Corporis Callosi & 19 & 124.53 & 17.13 & 107.49 & 9.99 & $0.0005^{\star \star}$ & 118.14 & 25.42 & 107.41 & 9.92 & 0.09 \\
\hline Nucleus Caudatus & 19 & 98.66 & 8.75 & 100.13 & 5.28 & 0.58 & 101.71 & 8.00 & 99.86 & 5.74 & 0.47 \\
\hline Putamen & 20 & 91.29 & 7.07 & 87.50 & 5.90 & 0.07 & 89.39 & 6.39 & 88.41 & 5.89 & 0.58 \\
\hline Globus Pallidus & 18 & 75.20 & 5.19 & 72.99 & 5.18 & 0.2 & 73.95 & 9.37 & 74.95 & 7.53 & 0.74 \\
\hline Thalamus & 20 & 108.63 & 10.94 & 104.51 & 5.22 & 0.12 & 107.27 & 7.64 & 104.52 & 8.35 & 0.27 \\
\hline Mesencephalon & 18 & 94.70 & 8.97 & 94.90 & 14.16 & 0.9 & 93.05 & 9.06 & 92.97 & 8.47 & 0.98 \\
\hline Upper Pons & 20 & 129.84 & 13.85 & 115.53 & 7.97 & $0.0011^{\star *}$ & 132.30 & 20.47 & 114.64 & 8.17 & $0.0013^{\star *}$ \\
\hline Lower Pons & 17 & 126.65 & 21.00 & 124.91 & 17.44 & 0.8 & 123.86 & 15.58 & 120.21 & 14.33 & 0.44 \\
\hline Cerebellar White Matter & 20 & 142.69 & 16.88 & 132.07 & 6.62 & $0.0145^{\star}$ & 140.88 & 18.43 & 133.61 & 9.58 & 0.12 \\
\hline Cerebellar Posterior Lobe & 17 & 137.90 & 15.20 & 136.88 & 11.28 & 0.79 & 143.65 & 24.95 & 131.93 & 13.88 & 0.08 \\
\hline
\end{tabular}

${ }^{1}$ Number of patient-control pairs.

**Significant after correction for multiple comparisons by using false-discovery rate (FDR).

${ }^{*} p<0.05$ but not significant after FDR correction.

TABLE 5 | Paired $t$-tests between patients and controls for T2' measured in brain hemisphere contralateral or ipsilateral to the more affected body side as indicated.

\begin{tabular}{|c|c|c|c|c|c|c|c|c|c|c|c|}
\hline \multirow[t]{3}{*}{ Region of Interest } & \multirow{3}{*}{$N^{1}$} & \multicolumn{5}{|c|}{ Ipsilateral } & \multicolumn{5}{|c|}{ Contralateral } \\
\hline & & \multicolumn{2}{|c|}{ Patient } & \multicolumn{2}{|c|}{ Control } & \multirow[t]{2}{*}{$p$} & \multicolumn{2}{|c|}{ Patient } & \multicolumn{2}{|c|}{ Control } & \multirow[t]{2}{*}{$p$} \\
\hline & & Mean & SD & Mean & SD & & Mean & SD & Mean & SD & \\
\hline Prefrontal Subcortical Area & 5 & 81.16 & 17.06 & 83.45 & 12.09 & 0.85 & 84.05 & 12.91 & 83.60 & 12.66 & 0.94 \\
\hline Subcortical Primary Motor Area & 17 & 56.00 & 7.27 & 57.10 & 10.60 & 0.70 & 60.73 & 10.73 & 59.03 & 8.00 & 0.63 \\
\hline Supplementary Motor Area & 13 & 66.68 & 15.24 & 64.86 & 9.75 & 0.67 & 67.57 & 8.51 & 74.06 & 9.21 & $0.0214^{\star}$ \\
\hline Centrum Semiovale & 17 & 69.58 & 8.41 & 69.53 & 7.31 & 0.99 & 70.72 & 10.79 & 69.64 & 11.34 & 0.77 \\
\hline Splenium Corporis Callosi & 18 & 53.85 & 12.63 & 51.68 & 7.62 & 0.40 & 55.92 & 11.71 & 48.51 & 7.26 & $0.024^{\star}$ \\
\hline Nucleus Caudatus & 16 & 57.79 & 12.06 & 56.19 & 8.28 & 0.65 & 58.62 & 18.24 & 61.98 & 15.36 & 0.63 \\
\hline Putamen & 17 & 47.21 & 9.53 & 49.73 & 14.36 & 0.53 & 49.56 & 11.51 & 44.67 & 8.44 & 0.21 \\
\hline Globus Pallidus & 10 & 36.15 & 5.15 & 33.84 & 8.85 & 0.56 & 34.68 & 6.20 & 27.32 & 5.81 & $0.0054^{*}$ \\
\hline Thalamus & 13 & 69.80 & 11.49 & 71.41 & 8.05 & 0.69 & 73.98 & 9.72 & 74.88 & 14.18 & 0.86 \\
\hline Mesencephalon & 5 & 30.22 & 7.01 & 28.39 & 10.06 & 0.80 & 28.59 & 8.10 & 37.24 & 8.20 & $0.035^{\star}$ \\
\hline Upper Pons & 11 & 24.96 & 9.64 & 25.80 & 8.68 & 0.84 & 26.11 & 9.70 & 30.57 & 10.63 & 0.40 \\
\hline Lower Pons & 17 & 41.54 & 18.20 & 38.66 & 12.11 & 0.53 & 38.47 & 13.63 & 37.89 & 11.75 & 0.89 \\
\hline Cerebellar White Matter & 15 & 46.88 & 18.83 & 41.98 & 12.24 & 0.44 & 46.66 & 16.29 & 40.63 & 9.61 & 0.17 \\
\hline Cerebellar Posterior Lobe & 15 & 41.26 & 12.45 & 37.85 & 21.22 & 0.61 & 44.40 & 13.48 & 40.45 & 15.92 & 0.41 \\
\hline
\end{tabular}

${ }^{1}$ Number of patient-control pairs.

**Significant after correction for multiple comparisons by using false-discovery rate (FDR).

${ }^{*} p<0.05$ but not significant after FDR correction.

An additional observation was the change in brain tissue relaxation time in the $\mathrm{PD}$ patients. We observed that $\mathrm{T} 1$ relaxation time was increased in 13 of 28 ROIs (bilateral prefrontal cortex, centrum semiovale, splenium corporis callosi, putamen, in contralateral primary motor area, supplementary motor area, caudate nucleus, mesencephalon, and in ipsilateral upper pons), further, the T2 relaxation time increased in bilateral upper pons, and in ipsilateral splenium corporis callosi and cerebellar white matter, and the $\mathrm{T} 2^{\prime}$ relaxation time increased in contralateral splenium corporis callosi and globus pallidus, and decreased in contralateral supplementary motor area and mesencephalon. While the exact underlying reason for observed 
TABLE 6 | Correlations of MDS-UPDRS to significant changes of relative proton density in respect to the most affected body side of the patients estimated by Spearman's correlation test ${ }^{1}$

\begin{tabular}{|c|c|c|c|c|c|c|c|c|c|c|c|c|c|}
\hline \multirow[t]{3}{*}{ Clinical scores } & \multicolumn{13}{|c|}{ Ipsilateral } \\
\hline & \multirow[b]{2}{*}{$N$} & \multicolumn{2}{|c|}{$\begin{array}{l}\text { Splenium } \\
\text { Corporis Callosi }\end{array}$} & \multicolumn{2}{|c|}{$\begin{array}{l}\text { Nucleus } \\
\text { Caudatus }\end{array}$} & \multicolumn{2}{|c|}{ Putamen } & \multicolumn{2}{|c|}{ Globus Pallidus } & \multicolumn{2}{|c|}{ Thalamus } & \multicolumn{2}{|c|}{ Mesencephalon } \\
\hline & & $R$ & $p$ & $R$ & $p$ & $R$ & $P$ & $R$ & $p$ & $R$ & $p$ & $R$ & $p$ \\
\hline UPDRS I & 20 & -0.072 & 0.763 & -0.179 & 0.449 & -0.165 & 0.487 & -0.160 & 0.499 & -0.062 & 0.795 & -0.068 & 0.775 \\
\hline UPDRS ॥ & 20 & -0.053 & 0.824 & -0.232 & 0.326 & -0.273 & 0.244 & -0.130 & 0.584 & 0.033 & 0.889 & 0.108 & 0.650 \\
\hline UPDRS III & 20 & -0.109 & 0.649 & 0.059 & 0.805 & 0.319 & 0.170 & 0.391 & 0.088 & 0.279 & 0.234 & 0.121 & 0.612 \\
\hline UPDRS IV & 20 & -0.084 & 0.725 & -0.156 & 0.511 & -0.270 & 0.249 & -0.288 & 0.217 & 0.102 & 0.668 & 0.038 & 0.875 \\
\hline UPDRS & 20 & -0.211 & 0.371 & -0.149 & 0.530 & 0.001 & 0.997 & 0.127 & 0.595 & 0.201 & 0.396 & 0.098 & 0.681 \\
\hline
\end{tabular}

\begin{tabular}{|c|c|c|c|c|c|c|c|c|c|c|c|c|c|c|c|c|c|}
\hline & \multicolumn{17}{|c|}{ Contralateral } \\
\hline & \multirow[b]{2}{*}{$N$} & \multicolumn{2}{|c|}{$\begin{array}{c}\text { Prefrontal } \\
\text { Subcortical Area }\end{array}$} & \multicolumn{2}{|c|}{$\begin{array}{c}\text { Splenium Corporis } \\
\text { Callosi }\end{array}$} & \multicolumn{2}{|c|}{$\begin{array}{l}\text { Nucleus } \\
\text { Caudatus }\end{array}$} & \multicolumn{2}{|c|}{ Putamen } & \multicolumn{2}{|c|}{ Thalamus } & \multicolumn{2}{|c|}{ Mesencephalon } & \multicolumn{2}{|c|}{ Upper Pons } & \multicolumn{2}{|c|}{ Lower Pons } \\
\hline & & $R$ & $p$ & $R$ & $p$ & $R$ & $P$ & $R$ & $p$ & $R$ & $p$ & $R$ & $p$ & $R$ & $p$ & $R$ & $p$ \\
\hline UPDRS I & 20 & -0.458 & $0.042^{*}$ & -0.170 & 0.473 & -0.372 & 0.106 & -0.335 & 0.148 & -0.234 & 0.321 & -0.202 & 0.393 & -0.110 & 0.645 & -0.085 & 0.722 \\
\hline UPDRS ॥ & 20 & -0.055 & 0.819 & -0.174 & 0.463 & -0.492 & $0.028^{*}$ & -0.357 & 0.123 & -0.323 & 0.164 & 0.030 & 0.902 & -0.147 & 0.535 & -0.036 & 0.882 \\
\hline UPDRS III & 20 & -0.068 & 0.776 & 0.132 & 0.579 & 0.051 & 0.830 & -0.187 & 0.430 & 0.048 & 0.840 & 0.027 & 0.910 & 0.086 & 0.720 & 0.035 & 0.885 \\
\hline UPDRS IV & 20 & 0.208 & 0.379 & -0.206 & 0.385 & -0.335 & 0.149 & -0.308 & 0.187 & -0.221 & 0.350 & 0.020 & 0.932 & -0.020 & 0.932 & -0.117 & 0.622 \\
\hline UPDRS & 20 & -0.149 & 0.530 & -0.156 & 0.511 & -0.317 & 0.174 & -0.333 & 0.151 & -0.164 & 0.489 & -0.069 & 0.771 & -0.014 & 0.952 & 0.005 & 0.982 \\
\hline
\end{tabular}

112 patients with more affected right body side and 8 with more affected left body side.

**Significant after correction for multiple comparisons by using false-discovery rate (FDR).

${ }^{*} p<0.05$ but not significant after FDR correction.

Hence, only regions with significant alterations in relative proton density were used for correlational analysis. 
parameter alterations in patients remains to be clarified, they all suggest certain PD-related changes in patients' brain tissue.

It is interesting to look at the altered qMRI parameters in distinct brain areas in respect to their neuroanatomic function and relevance in PD. Because of the small volume of the cortical gray matter, to allow for better reproducibility, and in accordance to earlier studies of our group, we decided to measure subcortical regions adjacent to the cerebral cortex. In the subcortical areas of interest, especially in the prefrontal subcortical area, we found decreased proton density that indicates reduced free water content, and increased $\mathrm{T} 1$ relaxation time indicating altered spatial conformation of brain tissue molecular structures. Both were pronounced in the contralateral hemisphere. In a normal aging cortex, T1 relaxation time decreases between the third and eighth decade of life (Steen et al., 1995; Cho et al., 1997; Suzuki et al., 2006; Saito et al., 2009). In a study of Gracien et al. (2017) the cortical decrease in T1 relaxation time with age was pronounced in the dorso-frontal and temporal cortex over a timespan of 7 years. The subcortical increase of T1 relaxation time adjacent to relevant cortical areas in the $\mathrm{PD}$ sample in this study might be associated with the loss of meso-cortical dopaminergic innervation and degeneration of unmyelinated dopaminergic axons. Adaptive processes might include a regression of dendrites and axons, leading to a decrease in free water fraction of those areas (Freeman et al., 2008; Thiessen et al., 2013; Gracien et al., 2017). These results were contradictory to recent data of Keil et al. (2020) in a study using magnetic resonance fingerprinting, in which they reported a cortical decrease in $\mathrm{T} 1$ relaxation time in PD patients. However, there seems to be very limited comparability of their data with the data obtained in our study due to severe differences in the methods used and the measurement of cortical gray matter compared to subcortical white matter area, as in the present study. Interestingly, relative proton density was not significantly correlated with normal aging in cortical gray matter brain structures in a recent study by Seiler et al. (2020). Further, we did not find significant changes in $\mathrm{T} 2$ and $\mathrm{T} 2{ }^{\prime}$ relaxation time in subcortical areas, suggesting that no significant gliosis, cell loss or tissue iron depositions were present (Fatouros et al., 1991; Gelman et al., 1999, 2001; Brex et al., 2000; Lutti et al., 2014).

In the basal ganglia pathway, a significant reduction of proton density in all dopamine innervated gray matter regions was found with pronunciation of the contralateral hemisphere to the clinical PD manifestation side in PD patients. Further, a prolongation of $\mathrm{T} 1$ relaxation time was found in the caudate nucleus and putamen contralaterally to the clinical PD manifestation side. T2 relaxation time revealed no significant changes in the subcortical structures, however, T2' relaxation time was significantly increased in the contralateral globus pallidus. These changes might correlate to a loss of dopaminergic innervation, aggregation of misfolded alphasynuclein, and adaptive degeneration of neuronal dendrites with reduction of the tissue free water content, as shown for the cortical areas (Freeman et al., 2008; Thiessen et al., 2013; Gracien et al., 2017). These findings have been confirmed in animal models of experimental Parkinsonism in the striatum (Villalba and Smith, 2010, 2013).
In the brain stem area, a significant reduction of proton density in the mesencephalon and pons was found, and T1 relaxation time was prolonged in the contralateral mesencephalon of the PD patients compared to matched controls. T2 relaxation time was prolonged in the contralateral mesencephalon which might be associated with cell death of the dopaminergic neurons and gliosis in the ventral mesencephalon. Further, T2' relaxation time was shortened in the contralateral mesencephalon, potentially linked to tissue iron accumulation. Degeneration of mesencephalic dopaminergic neurons is the main pathological hallmark of $\mathrm{PD}$, and several studies investigated microstructural changes in the substantia nigra or ventral mesencephalon. A decrease in $\mathrm{T} 2 *$ relaxation time in the substantia nigra of PD patients compared to healthy controls was reported by Egger et al. (2018) however, this decrease did not reach statistical significance. Decrease in T2* relaxation time was also reported in two studies of experimental Parkinsonism in a rat model of nigro-striatal denervation (Soria et al., 2011; Fang et al., 2018). Increased iron, copper and manganese concentrations in the substantia nigra were reported in a mouse model of experimental Parkinsonism (Matusch et al., 2012). Several other studies also reported significantly increased iron concentrations in the substantia nigra of PD patients compared to healthy controls by quantitative susceptibility mapping (Langkammer et al., 2016; Wang et al., 2016; Chen et al., 2019; Cheng et al., 2020). In a study of patients with neurodegeneration with brain iron accumulation (NBIA), thalamic and mesencephalic iron accumulation was also detected (McNeill et al., 2012).

The lack of significant alterations of the $\mathrm{T} 2$ ' sequences in the presented study of early PD patients could be due to counteracting processes in the brain stem areas. While neurodegeneration may lead to increased $\mathrm{T} 2$ ' relaxation time, the accumulation of iron in the dopaminergic areas was shown to lead to a decrease of T2' relaxation time (Siemonsen et al., 2008).

In the present study, no correlation between microstructural changes and PD symptoms measured by the MDS-UPDRS could be found after correction for multiple testing, despite of the distinguished profile of microstructural changes. Several other groups were also not able to find a correlation of clinical symptoms and changes in cerebral relaxometry (Nürnberger et al., 2017; Keil et al., 2020). Interestingly, a study in NBIA patients detected a significant correlation with dystonic symptoms (McNeill et al., 2012).

\section{Limitations}

The small sample size of the carefully characterized homogeneous group of early PD patients is the major limitation of the study. While efforts were made to minimize possible bias related to natural hemisphere laterality in the human brain, it may still have some impact on the results. Larger study samples can use these preliminary data to further evaluate microstructural changes as diagnostic tests for PD. In this study, manually set ROIs were used. Atlas-based methods or statistical mapping methods would be an alternative for an objective evaluation. For general clinical application, an automated mechanism would be more suitable. 
Further, the effect of PD therapy on microstructural changes is unclear and should be studied in future trials.

\section{CONCLUSION}

Parkinson's disease is associated with a distinct profile of microstructural changes which may accompany relevant pathological and maladaptive processes in disease pathophysiology. The technique used in this study offers new opportunities to study distinct aspects of PD pathology in vivo, and might contribute to early diagnosis both as a biomarker and a parameter for treatment efficiency in future trials. Future studies should evaluate the diagnostic value of combined structural, metabolic and microstructural changes in differential diagnosis of PD and atypical Parkinsonism.

\section{DATA AVAILABILITY STATEMENT}

The raw data supporting the conclusions of this article will be made available by the authors, without undue reservation.

\section{ETHICS STATEMENT}

The studies involving human participants were reviewed and approved by local Ethics Committee of Hannover Medical School

\section{REFERENCES}

Alvarez-Erviti, L., Couch, Y., Richardson, J., Cooper, J. M., and Wood, M. J. A. (2011). Alpha-synuclein release by neurons activates the inflammatory response in a microglial cell line. Neurosci. Res. 69, 337-342. doi: 10.1016/j.neures.2010. 12.020

Angelova, P. R., and Abramov, A. Y. (2017). Alpha-synuclein and beta-amyloid different targets, same players: calcium, free radicals and mitochondria in the mechanism of neurodegeneration. Biochem. Bioph. Res. Commun. 483, 1110-1115. doi: 10.1016/j.bbrc.2016.07.103

Benjamini, Y., and Hochberg, Y. (1995). Controlling the false discovery rate: A practical and powerful approach to multiple testing. J. R. Stat. Soc. Ser. B Methodol. 57, 289-300. doi: 10.1111/j.2517-6161.1995.tb02031.x

Braak, H., and Tredici, K. D. (2017). Neuropathological staging of brain pathology in sporadic Parkinson's disease: separating the wheat from the chaff. J. Parkinsons Dis. 7, S73-S87. doi: 10.3233/jpd-179001

Braak, H., Ghebremedhin, E., Rüb, U., Bratzke, H., and Tredici, K. D. (2004). Stages in the development of Parkinson's disease-related pathology. Cell Tissue Res. 318, 121-134. doi: 10.1007/s00441-004-0956-9

Brex, P. A., Parker, G. J. M., Leary, S. M., Molyneux, P. D., Barker, G. J., Davie, C. A., et al. (2000). Lesion heterogeneity in multiple sclerosis: a study of the relations between appearances on $\mathrm{T} 1$ weighted images, $\mathrm{T} 1$ relaxation times, and metabolite concentrations. J. Neurol. Neurosur. Psychiat. 68:627. doi: 10.1136/ jnnp.68.5.627

Burré, J., Sharma, M., and Südhof, T. C. (2018). Cell biology and pathophysiology of $\alpha$-synuclein. Cold Spring Harb. Perspect. Med. 8:a024091. doi: 10.1101/ cshperspect.a024091

Carey, D., Caprini, F., Allen, M., Lutti, A., Weiskopf, N., Rees, G., et al. (2018). Quantitative MRI provides markers of intra-, inter-regional, and age-related differences in young adult cortical microstructure. Neuroimage 182, 429-440. doi: 10.1016/j.neuroimage.2017.11.066

Chen, Q., Chen, Y., Zhang, Y., Wang, F., Yu, H., Zhang, C., et al. (2019). Iron deposition in Parkinson's disease by quantitative susceptibility mapping. BMC. Neurosci. 20:23. doi: 10.1186/s12868-019-0505-9
(No. 6167-2016). The patients/participants provided their written informed consent to participate in this study.

\section{AUTHOR CONTRIBUTIONS}

X-QD designed the study. MK and FW were responsible for recruitment. $\mathrm{MK}$ and $\mathrm{ME}$ performed the clinical characterization of the patients. NM, MA, and PN performed the MRIs. ME and $\mathrm{X}-\mathrm{QD}$ performed the statistical analysis. MK, ME, FW, and X-QD interpreted the data. $\mathrm{MK}, \mathrm{ME}$, and $\mathrm{X}-\mathrm{QD}$ wrote the manuscript. $\mathrm{NM}, \mathrm{GH}$, and HL coedited the manuscript. All authors had access to the complete data generated in the study and statistical analysis, took part in the manuscript edition, and agreed to submit the manuscript for publication.

\section{FUNDING}

This work was partially supported by the German Research Foundation (DFG) to X-QD.

\section{ACKNOWLEDGMENTS}

We would like to thank all participants of this study.

Cheng, Q., Huang, J., Liang, J., Ma, M., Zhao, Q., Lei, X., et al. (2020). Evaluation of abnormal iron distribution in specific regions in the brains of patients with Parkinson's disease using quantitative susceptibility mapping and R2* mapping. Exp. Ther. Med. 19, 3778-3786. doi: 10.3892/etm.2020.8645

Cho, S., Jones, D., Reddick, W. E., Ogg, R. J., and Steen, R. G. (1997). Establishing norms for age-related changes in proton $\mathrm{T} 1$ of human brain tissue in vivo. Magn. Reson. Imaging 15, 1133-1143. doi: 10.1016/s0730-725x(97) 00202-6

Depboylu, C., Schäfer, M. K.-H., Arias-Carrión, O., Oertel, W. H., Weihe, E., and Höglinger, G. U. (2011a). Possible involvement of complement factor C1q in the clearance of extracellular neuromelanin from the substantia nigra in Parkinson disease. J. Neuropathol. Exp. Neurol. 70, 125-132. doi: 10.1097/nen. 0b013e31820805b9

Depboylu, C., Schorlemmer, K., Klietz, M., Oertel, W. H., Weihe, E., Höglinger, G. U., et al. (2011b). Upregulation of microglial C1q expression has no effects on nigrostriatal dopaminergic injury in the MPTP mouse model of Parkinson disease. J. Neuroimmunol. 236, 39-46. doi: 10.1016/j.jneuroim.2011. 05.006

Egger, K., Amtage, F., Yang, S., Obmann, M., Schwarzwald, R., Köstering, L., et al. (2018). T2* relaxometry in patients with Parkinson's disease. Clin. Neuroradiol. 28, 63-67. doi: 10.1007/s00062-016-0523-2

Eylers, V. V., Maudsley, A. A., Bronzlik, P., Dellani, P. R., Lanfermann, H., and Ding, X. Q. (2016). Detection of normal aging effects on human brain metabolite concentrations and microstructure with whole-brain MR spectroscopic imaging and quantitative MR imaging. Am. J. Neuroradiol. 37, 447-454.

Fang, Y., Zheng, T., Liu, L., Gao, D., Shi, Q., Dong, Y., et al. (2018). Role of the combination of FA and parameters as a new diagnostic method in therapeutic evaluation of parkinson's disease. J. Magn. Reson. Imag. 48, 84-93. doi: 10.1002/ jmri.25900

Fatouros, P. P., Marmarou, A., Kraft, K. A., Inao, S., and Schwarz, F. P. (1991). In vivo brain water determination by $\mathrm{T} 1$ measurements: effect of total water content, hydration fraction, and field strength. Magnet. Reson. Med. 17, 402413. doi: $10.1002 / \mathrm{mrm} .1910170212$ 
Filo, S., Shtangel, O., Salamon, N., Kol, A., Weisinger, B., Shifman, S., et al. (2019). Disentangling molecular alterations from water-content changes in the aging human brain using quantitative MRI. Nat. Commun. 10:3403. doi: 10.1038/ s41467-019-11319-1

Freeman, S. H., Kandel, R., Cruz, L., Rozkalne, A., Newell, K., Frosch, M. P., et al. (2008). Preservation of neuronal number despite age-related cortical brain atrophy in elderly subjects without Alzheimer disease. J. Neuropath Exp. Neur. 67, 1205-1212. doi: 10.1097/nen.0b013e31818fc72f

Fu, T., Klietz, M., Nösel, P., Wegner, F., Schrader, C., Höglinger, G. U., et al. (2020). Brain morphological alterations are detected in early-stage Parkinson's disease with MRI morphometry. J. Neuroimag. 30, 786-792. doi: 10.1111/jon.12769

Gelman, N., Ewing, J. R., Gorell, J. M., Spickler, E. M., and Solomon, E. G. (2001). Interregional variation of longitudinal relaxation rates in human brain at 3.0 T: Relation to estimated iron and water contents. Magnet. Reson. Med. 45, 71-79.

Gelman, N., Gorell, J. M., Barker, P. B., Savage, R. M., Spickler, E. M., Windham, J. P., et al. (1999). MR imaging of human brain at 3.0 T: preliminary report on transverse relaxation rates and relation to estimated iron content. Radiology 210, 759-767. doi: 10.1148/radiology.210.3.r99fe41759

Goetz, C. G., Tilley, B. C., Shaftman, S. R., Stebbins, G. T., Fahn, S., MartinezMartin, P., et al. (2008). Movement Disorder Society-sponsored revision of the Unified Parkinson's Disease Rating Scale (MDS-UPDRS): Scale presentation and clinimetric testing results. Movement Disord. 23, 2129-2170. doi: 10.1002/ mds. 22340

Gracien, R.-M., Nürnberger, L., Hok, P., Hof, S.-M., Reitz, S. C., Rüb, U., et al. (2017). Evaluation of brain ageing: a quantitative longitudinal MRI study over 7 years. Eur. Radiol. 27, 1568-1576. doi: 10.1007/s00330-016-4485- 1

Gracien, R.-M., Petrov, F., Hok, P., Wijnen, A., van, Maiworm, M., et al. (2019). Multimodal quantitative MRI reveals no evidence for tissue pathology in idiopathic cervical dystonia. Front. Neurol. 10:914. doi: 10.3389/fneur.2019. 00914

Greten, S., Müller-Funogea, J. I., Wegner, F., Höglinger, G. U., Simon, N., Junius-Walker, U., et al. (2020). Drug safety profiles in geriatric patients with Parkinson's disease using the FORTA (Fit fOR The Aged) classification: results from a mono-centric retrospective analysis. J. Neural. Transm. 128, 49-60. doi: 10.1007/s00702-020-02276-x

Halliday, G. M., and McCann, H. (2010). The progression of pathology in Parkinson's disease. Ann. N.Y. Acad. Sci. 1184, 188-195. doi: 10.1111/j.17496632.2009.05118.x

Heinzel, S., Berg, D., Binder, S., Ebersbach, G., Hickstein, L., Herbst, H., et al. (2018). Do we need to rethink the epidemiology and healthcare utilization of Parkinson's disease in Germany? Front. Neurol. 9:500. doi: 10.3389/fneur.2018. 00500

Huppertz, H., Möller, L., Südmeyer, M., Hilker, R., Hattingen, E., Egger, K., et al. (2016). Differentiation of neurodegenerative parkinsonian syndromes by volumetric magnetic resonance imaging analysis and support vector machine classification. Movement Disord. 31, 1506-1517. doi: 10.1002/mds. 26715

Jellinger, K. A. (2019). Is Braak staging valid for all types of Parkinson's disease? J. Neural. Transm. 126, 423-431. doi: 10.1007/s00702-018-1898-9

Jurcoane, A., Wagner, M., Schmidt, C., Mayer, C., Gracien, R., Hirschmann, M., et al. (2013). Within-lesion differences in quantitative MRI parameters predict contrast enhancement in multiple sclerosis. J. Magn. Reson Imag. 38, 1454-1461. doi: 10.1002/jmri.24107

Kalbe, E., Kessler, J., Calabrese, P., Smith, R., Passmore, A. P., Brand, M., et al. (2004). DemTect: a new, sensitive cognitive screening test to support the diagnosis of mild cognitive impairment and early dementia. Int. J. Geriatr. Psych. 19, 136-143. doi: 10.1002/gps.1042

Kalia, L. V., and Kalia, S. K. (2015). Alpha-synuclein and lewy pathology in Parkinson's disease. Curr. Opin. Neurol. 28, 375-381. doi: 10.1097/wco. 0000000000000215

Keber, U., Klietz, M., Carlsson, T., Oertel, W. H., Weihe, E., Schäfer, M. K.H., et al. (2015). Striatal tyrosine hydroxylase-positive neurons are associated with 1-DOPA-induced dyskinesia in hemiparkinsonian mice. Neuroscience 298, 302-317. doi: 10.1016/j.neuroscience.2015.04.021

Keil, V. C., Bakoeva, S. P., Jurcoane, A., Doneva, M., Amthor, T., Koken, P., et al. (2020). A pilot study of magnetic resonance fingerprinting in Parkinson's disease. NMR Biomed. 33:e4389. doi: 10.1002/nbm.4389
Klietz, M., Bronzlik, P., Nösel, P., Wegner, F., Dressler, D. W., Dadak, M., et al. (2019a). Altered neurometabolic profile in early Parkinson's disease: A study with short echo-time whole brain MR spectroscopic imaging. Front. Neurol. 10:777. doi: 10.3389/fneur.2019.00777

Klietz, M., Greten, S., Wegner, F., and Höglinger, G. U. (2019b). Safety and tolerability of pharmacotherapies for Parkinson's disease in geriatric patients. Drug Aging 36, 511-530. doi: 10.1007/s40266-019-00654-z

Klietz, M., Keber, U., Carlsson, T., Chiu, W.-H., Höglinger, G. U., Weihe, E., et al. (2016). 1-DOPA-induced dyskinesia is associated with a deficient numerical downregulation of striatal tyrosine hydroxylase mRNA-expressing neurons. Neuroscience 331, 120-133. doi: 10.1016/j.neuroscience.2016. 06.017

Klietz, M., Schnur, T., Drexel, S., Lange, F., Tulke, A., Rippena, L., et al. (2020). Association of motor and cognitive symptoms with health-related quality of life and caregiver burden in a german cohort of advanced Parkinson's disease patients. Parkinsons Dis. 2020:5184084. doi: 10.1155/2020/ 5184084

Klietz, M., Tulke, A., Müschen, L. H., Paracka, L., Schrader, C., Dressler, D. W., et al. (2018). Impaired quality of life and need for palliative care in a german cohort of advanced Parkinson's disease patients. Front. Neurol. 9:120. doi: 10. 3389/fneur.2018.00120

Langkammer, C., Pirpamer, L., Seiler, S., Deistung, A., Schweser, F., Franthal, S., et al. (2016). Quantitative susceptibility mapping in Parkinson's disease. Plos One 11:e0162460. doi: 10.1371/journal.pone.0162460

Laule, C., Vavasour, I. M., Moore, G. R. W., Oger, J., Li, D. K. B., Paty, D. W., et al. (2004). Water content and myelin water fraction in multiple sclerosis. J. Neurol. 251, 284-293. doi: 10.1007/s00415-004-0306-6

Lutti, A., Dick, F., Sereno, M. I., and Weiskopf, N. (2014). Using high-resolution quantitative mapping of R1 as an index of cortical myelination. Neuroimage 93, 176-188. doi: 10.1016/j.neuroimage.2013.06.005

Matusch, A., Fenn, L. S., Depboylu, C., Klietz, M., Strohmer, S., McLean, J. A., et al. (2012). Combined elemental and biomolecular mass spectrometry imaging for probing the inventory of tissue at a micrometer scale. Anal. Chem. 84, 3170-3178. doi: 10.1021/ac203112c

McNeill, A., Gorman, G., Khan, A., Horvath, R., Blamire, A. M., and Chinnery, P. F. (2012). Progressive brain iron accumulation in neuroferritinopathy measured by the thalamic T2* relaxation rate. Am. J. Neuroradiol. 33, 1810-1813. doi: 10.3174/ajnr.a3036

Meijer, F. J. A., and Goraj, B. (2014). Brain MRI in Parkinson s disease. Front. Biosci. 6, 360-369. doi: 10.2741/e711

Nürnberger, L., Gracien, R.-M., Hok, P., Hof, S.-M., Rüb, U., Steinmetz, H., et al. (2017). Longitudinal changes of cortical microstructure in Parkinson's disease assessed with T1 relaxometry. Neuroimage Clin. 13, 405-414. doi: 10.1016/j.nicl. 2016.12.025

Olanow, C. W., and Prusiner, S. B. (2009). Is Parkinson's disease a prion disorder? Proc. National. Acad. Sci. 106, 12571-12572. doi: 10.1073/pnas.09067 59106

Postuma, R. B., Berg, D., Stern, M., Poewe, W., Olanow, C. W., Oertel, W., et al. (2015). MDS clinical diagnostic criteria for Parkinson's disease. Movement. Disord. 30, 1591-1601. doi: 10.1002/mds.26424

Rai, S. N., and Singh, P. (2020). Advancement in the modelling and therapeutics of Parkinson's disease. J. Chem. Neuroanat. 104:101752. doi: 10.1016/j.jchemneu. 2020.101752

Rai, S. N., Birla, H., Singh, S. S., Zahra, W., Patil, R. R., Jadhav, J. P., et al. (2017). Mucuna pruriens Protects against MPTP Intoxicated Neuroinflammation in Parkinson's Disease through NF-кB/pAKT Signaling Pathways. Front. Aging Neurosci. 9:421. doi: 10.3389/fnagi.2017.00421

Rai, S. N., Chaturvedi, V. K., Singh, P., Singh, B. K., and Singh, M. P. (2020). Mucuna pruriens in Parkinson's and in some other diseases: recent advancement and future prospective. 3 Biotech. 10:522. doi: 10.1007/s13205020-02532-7

Rai, S. N., Yadav, S. K., Singh, D., and Singh, S. P. (2016). Ursolic acid attenuates oxidative stress in nigrostriatal tissue and improves neurobehavioral activity in MPTP-induced Parkinsonian mouse model. J. Chem. Neuroanat. 71, 41-49. doi: 10.1016/j.jchemneu.2015.12.002

Rai, S., Singh, P., Varshney, R., Chaturvedi, V., Vamanu, E., Singh, M., et al. (2021). Promising drug targets and associated therapeutic interventions in Parkinson's disease. Neural. Regen. Res. 16:1730. doi: 10.4103/1673-5374.306066 
Reas, E. T., Hagler, D. J., White, N. S., Kuperman, J. M., Bartsch, H., Wierenga, C. E., et al. (2018). Microstructural brain changes track cognitive decline in mild cognitive impairment. Neuroimage Clin. 20, 883-891. doi: 10.1016/j.nicl.2018. 09.027

Riederer, P., and Sian-Hülsmann, J. (2012). The significance of neuronal lateralisation in Parkinson's disease. J. Neural. Transm. 119, 953-962. doi: 10. 1007/s00702-012-0775-1

Saito, N., Sakai, O., Ozonoff, A., and Jara, H. (2009). Relaxo-volumetric multispectral quantitative magnetic resonance imaging of the brain over the human lifespan: global and regional aging patterns. Magn. Reson. Imag. 27, 895-906. doi: 10.1016/j.mri.2009.05.006

Seiler, A., Schöngrundner, S., Stock, B., Nöth, U., Hattingen, E., Steinmetz, H., et al. (2020). Cortical aging - new insights with multiparametric quantitative MRI. Aging 12, 16195-16210. doi: 10.18632/aging.103629

Sheng, Z.-H., and Cai, Q. (2012). Mitochondrial transport in neurons: impact on synaptic homeostasis and neurodegeneration. Nat. Rev. Neurosci. 13, 77-93. doi: $10.1038 / \mathrm{nrn} 3156$

Siemonsen, S., Finsterbusch, J., Matschke, J., Lorenzen, A., Ding, X.-Q., and Fiehler, J. (2008). Age-Dependent Normal Values of T2* and T2' in Brain Parenchyma. Am. J. Neuroradiol. 29, 950-955. doi: 10.3174/ajnr.a0951

Soria, G., Aguilar, E., Tudela, R., Mullol, J., Planas, A. M., and Marin, C. (2011). In vivo magnetic resonance imaging characterization of bilateral structural changes in experimental Parkinson's disease: a T2 relaxometry study combined with longitudinal diffusion tensor imaging and manganese-enhanced magnetic resonance imaging in the 6-hydroxydopamine rat model. Eur. J. Neurosci. 33, 1551-1560. doi: 10.1111/j.1460-9568.2011.07639.x

Steen, R. G., Gronemeyer, S. A., and Taylor, J. S. (1995). Age-related changes in proton T1 values of normal human brain. J. Magn. Reson Imag. 5, 43-48. doi: 10.1002/jmri.1880050111

Stöckl, M. T., Zijlstra, N., and Subramaniam, V. (2013). $\alpha$-Synuclein oligomers: An amyloid pore? Mol. Neurobiol. 47, 613-621. doi: 10.1007/s12035-012-8331-4

Suzuki, S., Sakai, O., and Jara, H. (2006). Combined volumetric T1, T2 and secularT2 quantitative MRI of the brain: age-related global changes (preliminary results). Magn. Reson. Imag. 24, 877-887. doi: 10.1016/j.mri.2006.04.011

Thiessen, J. D., Zhang, Y., Zhang, H., Wang, L., Buist, R., Bigio, M. R. D., et al. (2013). Quantitative MRI and ultrastructural examination of the cuprizone mouse model of demyelination. NMR Biomed. 26, 1562-1581. doi: 10.1002/ nbm. 2992

Titova, N., Martinez-Martin, P., Katunina, E., and Chaudhuri, K. R. (2017). Advanced Parkinson's or “complex phase” Parkinson's disease? Re-evaluation is needed. J. Neural. Transm. 124, 1529-1537. doi: 10.1007/s00702-017-1799-3

Tofts, P. (2018). Quantitative MRI of the Brain measuring changes caused by disease. Hoboken, NJ: John Wiley \& Sons, Ltd.

Tomlinson, C. L., Stowe, R., Patel, S., Rick, C., Gray, R., and Clarke, C. E. (2010). Systematic review of levodopa dose equivalency reporting in Parkinson's disease. Movement. Disord. 25, 2649-2653. doi: 10.1002/mds.23429
Villalba, R. M., and Smith, Y. (2010). Striatal Spine Plasticity in Parkinson's Disease. Front. Neuroanat. 4:133. doi: 10.3389/fnana.2010.00133

Villalba, R. M., and Smith, Y. (2013). Differential striatal spine pathology in Parkinson's disease and cocaine addiction: A key role of dopamine? Neuroscience 251, 2-20. doi: 10.1016/j.neuroscience.2013.07.011

Waehnert, M. D., Dinse, J., Schäfer, A., Geyer, S., Bazin, P.-L., Turner, R., et al. (2016). A subject-specific framework for in vivo myeloarchitectonic analysis using high resolution quantitative MRI. Neuroimage 125, 94-107. doi: 10.1016/ j.neuroimage.2015.10.001

Wagner, M., Jurcoane, A., Volz, S., Magerkurth, J., Zanella, F. E., NeumannHaefelin, T., et al. (2012). Age-related changes of cerebral autoregulation: New insights with quantitative $\mathrm{T}^{2}$ '-mapping and pulsed arterial spin-labeling MR imaging. Am. J. Neuroradiol. 33, 2081-2087. doi: 10.3174/ajnr.a3138

Wang, J.-Y., Zhuang, Q.-Q., Zhu, L.-B., Zhu, H., Li, T., Li, R., et al. (2016). Metaanalysis of brain iron levels of Parkinson's disease patients determined by postmortem and MRI measurements. Sci. Rep. 6:36669.

Wearn, A. R., Nurdal, V., Saunders-Jennings, E., Knight, M. J., Isotalus, H. K., Dillon, S., et al. (2020). T2 heterogeneity: a novel marker of microstructural integrity associated with cognitive decline in people with mild cognitive impairment. Alzheimer's Res. Ther. 12:105. doi: 10.1186/s13195-02000672-9

Yekhlef, F., Ballan, G., Macia, F., Delmer, O., Sourgen, C., and Tison, F. (2003). Routine MRI for the differential diagnosis of Parkinson's disease, MSA, PSP, and CBD. J. Neural. Transm. 110, 151-169.

Zhang, W., Wang, T., Pei, Z., Miller, D. S., Wu, X., Block, M. L., et al. (2005). Aggregated $\alpha$-synuclein activates microglia: a process leading to disease progression in Parkinson's disease. FASEB J. 19, 533-542. doi: 10.1096/fj.042751com

Conflict of Interest: The authors declare that the research was conducted in the absence of any commercial or financial relationships that could be construed as a potential conflict of interest.

Publisher's Note: All claims expressed in this article are solely those of the authors and do not necessarily represent those of their affiliated organizations, or those of the publisher, the editors and the reviewers. Any product that may be evaluated in this article, or claim that may be made by its manufacturer, is not guaranteed or endorsed by the publisher.

Copyright (C) 2021 Klietz, Elaman, Mahmoudi, Nösel, Ahlswede, Wegner, Höglinger, Lanfermann and Ding. This is an open-access article distributed under the terms of the Creative Commons Attribution License (CC BY). The use, distribution or reproduction in other forums is permitted, provided the original author(s) and the copyright owner(s) are credited and that the original publication in this journal is cited, in accordance with accepted academic practice. No use, distribution or reproduction is permitted which does not comply with these terms. 